\title{
State-and-Transition Models for Heterogeneous Landscapes: A Strategy for Development and Application
}

\author{
Brandon T. Bestelmeyer, ${ }^{1}$ Arlene J. Tugel, ${ }^{2}$ George L. Peacock, Jr., ${ }^{3}$ Daniel G. Robinett, ${ }^{4}$ \\ Pat L. Shaver, ${ }^{5}$ Joel R. Brown, ${ }^{2}$ Jeffrey E. Herrick, ${ }^{6}$ Homer Sanchez, ${ }^{7}$ and Kris M. Haustad ${ }^{8}$ \\ Authors are ${ }^{1}$ Research Ecologist, ${ }^{6}$ Research Scientist, and ${ }^{8}$ Research Leader, US Department of Agriculture-Agricultural Research Service (USDA-ARS), \\ Jornada Experimental Range, New Mexico State University, Box 30003 MSC 3JER, Las Cruces, NM 88003, USA; ${ }^{2}$ Soil Scientists, USDA Natural Resources \\ Conservation Service (NRCS), Jornada Experimental Range, New Mexico State University, Box 30003 MSC 3JER, Las Cruces, NM 88003, USA; ${ }^{3}$ Team \\ Leader-Grazing Lands, and ${ }^{7}$ Rangeland Management Specialist, USDA-NRCS Central National Technology Support Center, PO Box 6567, Fort Worth, \\ TX 76115, USA; ${ }^{4}$ Rangeland Consultant, Robinett Rangeland Resources LLC, 16900 N Forecastle, Tucson, AZ 85739, USA; and ${ }^{5}$ Rangeland Management \\ Specialist, USDA-NRCS West National Technology Support Center, 1201 NE Lloyd Blvd, Suite 1000, Portland, OR 97232, USA.
}

\begin{abstract}
Interpretation of assessment and monitoring data requires information about how reference conditions and ecological resilience vary in space and time. Reference conditions used as benchmarks are often specified via potential-based land classifications (e.g., ecological sites) that describe the plant communities potentially observed in an area based on soil and climate. State-and-transition models (STMs) coupled to ecological sites specify indicators of ecological resilience and thresholds. Although general concepts surrounding STMs and ecological sites have received increasing attention, strategies to apply and quantify these concepts have not. In this paper, we outline concepts and a practical approach to potential-based land classification and STM development. Quantification emphasizes inventory techniques readily available to natural resource professionals that reveal processes interacting across spatial scales. We recommend a sequence of eight steps for the co-development of ecological sites and STMs, including 1) creation of initial concepts based on literature and workshops; 2) extensive, low-intensity traverses to refine initial concepts and to plan inventory; 3 ) development of a spatial hierarchy for sampling based on climate, geomorphology, and soils; 4) stratified medium-intensity inventory of plant communities and soils across a broad extent and with large sample sizes; 5) storage of plant and soil data in a single database; 6) model-building and analysis of inventory data to test initial concepts; 7) support and/ or refinement of concepts; and 8) high-intensity characterization and monitoring of states. We offer a simple example of how data assembled via our sequence are used to refine ecological site classes and STMs. The linkage of inventory to expert knowledge and site-based mechanistic experiments and monitoring provides a powerful means for specifying management hypotheses and, ultimately, promoting resilience in grassland, shrubland, savanna, and forest ecosystems.
\end{abstract}

\section{Resumen}

La interpretación de la evaluación y el monitoreo de datos, exigen que haya información de cómo las condiciones de referencia y resistencia ecológica varían en espacio y tiempo. Las condiciones de referencia que se usan como puntos de comparación se describen a menudo mediante las clasificaciones de terrenos basándose en su potencial (por ejemplo, sitio ecológico) de comunidades de plantas presentes en un área, en base a suelo y clima. Los Modelos de Estado y Transición (METs) relacionados a sitios ecológicos, son indicadores específicos de los límites de resistencia ecológica. Aunque se ha dado mucha atención a los conceptos generales que rodean los METs y los sitios ecológicos, no ha sido así con las estrategias para aplicar y calificar esos conceptos. En este trabajo, damos una idea general de los conceptos y un enfoque práctico para la clasificación de terrenos en base a su potencial, así como para el desarrollo de METs. La calificación enfatiza técnicas de inventario fácilmente accesibles a los profesionales en recursos naturales presentando un proceso de interacción a través de escalas espaciales. Nosotros recomendamos una secuencia de ocho pasos para el desarrollo de sitios ecológicos y METs, como son: 1) creación de conceptos iniciales basados en literatura y talleres; 2) extensivos viajes de reconocimiento para el refinamiento de los conceptos iniciales y planear el inventario; 3) desarrollo de una escala espacial para muestreo, basándose en clima, forma del terreno, y suelos; 4) estratificación de inventario de media intensidad de las comunidades de plantas y suelos a través de una gran cantidad de muestras de tamaño grande; 5) almacenamiento de datos de plantas y suelos en una sola base de datos; 6) construcción del modelo y análisis de los datos inventariados para evaluar los conceptos iníciales; 7) apoyo y/o refinamiento de conceptos; y 8) intensa caracterización y monitoreo de las situaciones. Ofrecemos, además, un ejemplo sencillo de cómo colectar los datos, mediante el uso de nuestra secuencia para refinar la clase de sitio ecológico y los METs. El enlace del inventario con el conocimiento experto y la mecánica de

Research was funded in part by appropriated funds to the USDA-ARS Jornada Experimental Range, Bureau of Land Management, New Mexico, and the Jornada Basin Long-Term Ecological Research project (DEB 0618210).

Mention of a proprietary product does not constitute a guarantee or warranty of the product by USDA or the authors and does not imply its approval to the exclusion of the other products that also may be suitable.

Correspondence: Brandon T. Bestelmeyer, USDA-ARS Jornada Experimental Range, New Mexico State University, Box 30003 MSC 3JER, Las Cruces, NM 88003, USA. Email: bbestelm@nmsu.edu

Manuscript received 3 June 2008; manuscript accepted 8 October 2008. 
experimentos y monitoreo basados en el potencial de sitio, proporciona un medio efectivo para especificar hipótesis de manejo y finalmente para promover la recuperación de pastizales, matorrales, sabanas, y ecosistemas forestales.

Key Words: climate, dynamic soil properties, ecological sites, inventory, monitoring, quantile regression, soils, state-andtransition models, threshold

\section{INTRODUCTION}

Assessment, monitoring, and management efforts require information about both the ecosystem conditions targeted by management and the relationship of indicators to ecosystem change. In natural resources management, two interrelated tools have emerged to provide this information: potential-based land classification and state-and-transition models (Herrick et al. 2006). Land classifications account for spatial variation in reference (i.e., potential, properly-functioning, healthy, or desirable) conditions and the processes driving changes to ecosystems (e.g., Hobbs and McIntyre 2005; Kunst et al. 2006; Wessels et al. 2008; Gallant et al. in press). Without spatiallyexplicit expectations, "one-size-fits-all" and partisan thinking often circumvent sound management decisions (Swetnam et al. 1999). State-and-transition models (hereafter STMs), including similar conceptual models, identify patterns and mechanisms of ecosystem response to natural and anthropogenic drivers. The models feature the possibility of threshold behavior in which transitions to alternative ecosystem states occur that are difficult to reverse. STMs are a widely-used means to interpret assessment and monitoring data and to design management actions (Carpenter and Brock 2006; Forbis et al. 2006; King and Hobbs 2006; Kunst et al. 2006; Barbour et al. 2007; Fancy et al. in press). Coupling land classification to STMs allows managers to adjust expectations, measurements, interpretations, and management responses to variation within landscapes and regions.

Land units called "ecological sites" in the United States and similar potential-based land classification systems provide a basis for linking spatial data to specific reference conditions and STMs (Christian 1958; Dyksterhuis 1958; Shiflet 1973; Creque et al. 1999; Winthers et al. 2005). Ecological site classifications are based on the fundamental idea that differences in potential plant communities and their resilience are governed by subtle differences in soil, geomorphology, and climate (e.g., McAuliffe 1994; Fuhlendorf and Smeins 1998; Bestelmeyer et al. 2006; Hughes et al. 2006; Buxbaum and Vanderbilt 2007; McAuliffe et al. 2007). Ecological site classes are distinguished by significant differences in potential vegetation composition or production between soils or by differences in the process by which the reference states of those soils change to alternative states (US Department of Agriculture-Natural Resources Conservation Service [USDANRCS] 2003). Due to the importance of soil variability, ecological sites are finer-grained than most existing land classifications. Ecological sites are nested within climate-based classes called Land Resource Units or Major Land Resource Areas (MLRAs; similar to ecoregions). In contrast to classifications based on existing vegetation, ecological sites are distinguished by climate, geomorphic setting, and soil, alongside vegetation. Each ecological site features a distinctive STM that can contain several alternative plant communities (Bestelmeyer et al. 2004).

STMs serve three primary functions. First, STMs contrast the properties of reference and alternative states (Friedel 1991;
Scheffer and Carpenter 2003). Second, STMs describe the mechanisms by which transitions among states occur (Westoby et al. 1989). In doing so, the models identify particular patterns, such as levels of vegetation cover in the reference state, that indicate the risk of a transition to an alternative state (Bestelmeyer et al. 2003; Briske et al. 2008). Triggers (such as drought) act on low-resilience systems to initiate transitions. Third, STMs describe the point at which soil or plant community changes preclude autogenic recovery and require energy-intensive measures to reverse (i.e., thresholds; Stringham et al. 2003). It is hoped that assessment and monitoring data compared with information in STMs can be used to prevent persistent degradation and target restoration actions where benefits are most likely to be realized.

Management areas often encompass landscapes featuring large differences in reference states and ecological resilience. Soil and climate maps connected to ecological site classifications reflect information represented in several STMs pertaining to a given landscape. In the United States, National Cooperative Soil Survey and the USDA-NRCS have connected soil mapping with the development of ecological site classes and STMs. Data and interpretations pertaining to an ecological site, including the STM, are summarized in a report called an Ecological Site Description (ESD). Ecological sites and associated interpretations are represented spatially via soil map units. The map units can feature one or more soil map unit components-often more than one when distinct soil types are finely intermingled and not resolvable with a given mapping effort. Functionally-distinct components are associated with distinct ecological sites. When made spatially explicit in maps and then identified in the field, ecological sites and alternative states provide a logical basis for the design of assessment, monitoring, and management efforts in heterogeneous landscapes.

In spite of efforts to refine the conceptual elements of STMs and ecological sites (see Table 1 for elements and their definitions), there are often few data assembled to provide a quantitative basis for them. One reason is the historical emphasis on documentation of reference conditions using intensive measurements at a few locations, but not on the systematic production of large datasets suitable for statistical analysis. Furthermore, the concepts and tools we use to interpret ecosystem change have improved in the last decade, especially with respect to the linkage of plants and soil function (Tugel et al. 2005). Consequently, existing data often are not sufficient to distinguish key ecological site attributes, states, or functions. Data limitations have precluded evaluation, refinement, and (in some cases) acceptance of ecological sites and STMs by the science and management communities.

In this paper, we offer a general strategy to overcome limitations in the codevelopment of ecological sites and STMs. Our strategy emphasizes the integration of vegetation and soil inventory with expert knowledge, long-term studies, and experimentation. We emphasize inventory as a primary source of data because long-term studies and experiments vary in 
Table 1. A description of key elements of ecological sites and state-and-transition models (STMs) discussed in this paper. Definitions for some ecological site elements adapted from US Department of Agriculture-Natural Resources Conservation Service (2007). Definitions for STM elements adapted from Briske et al. (2008).

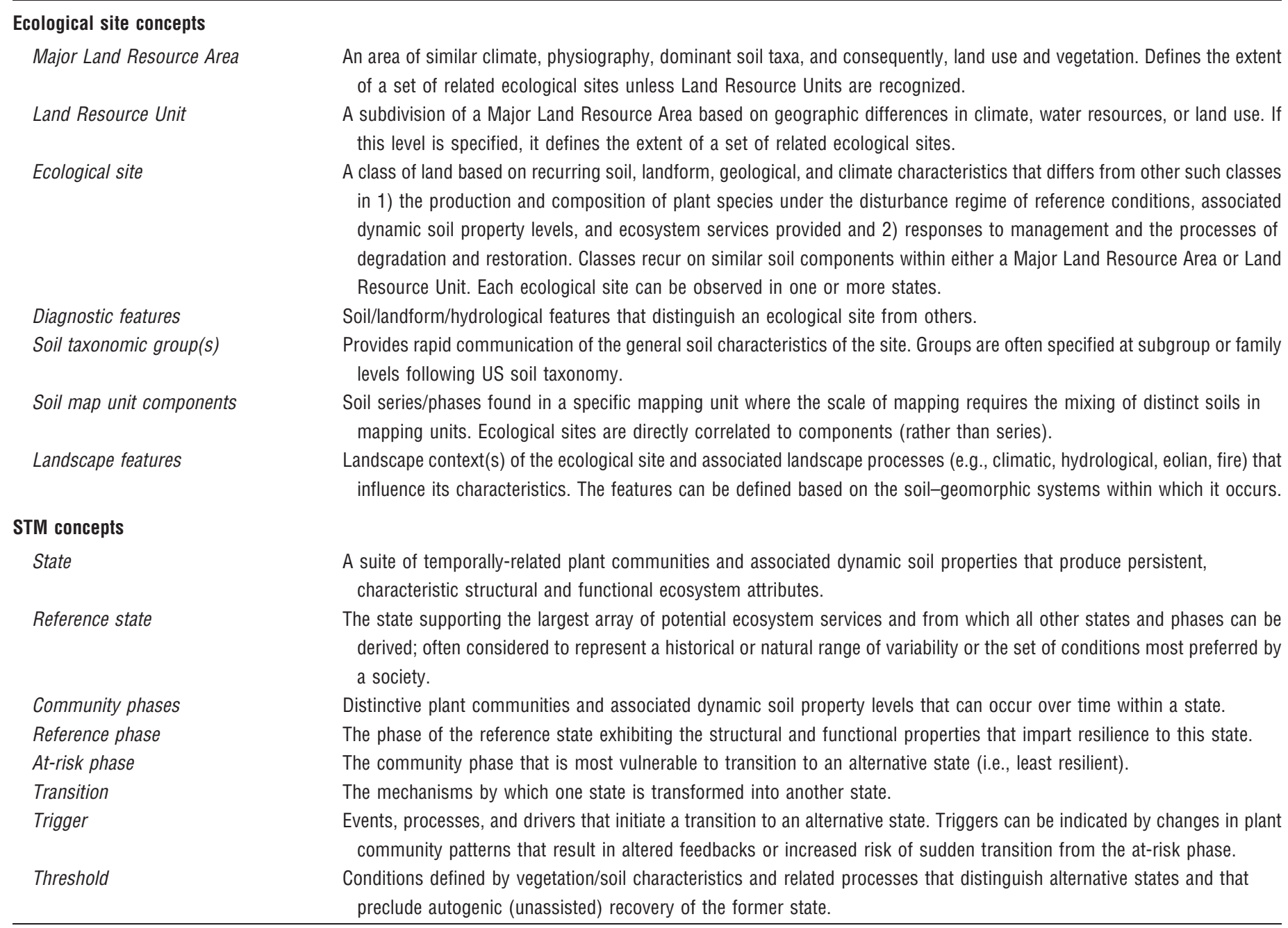

availability and are difficult to complete quickly. First, we describe steps in a framework that link regional inventory to expert knowledge and available data. A key component of the framework is a hierarchical stratification of a region according to the cross-scale processes that govern transitions among states. Second, we provide an example analysis of inventory data that relates the occurrence of alternative states to soil variables. We discuss how inferences drawn from such an analysis are linked to expert knowledge, site-based mechanistic experiments, and monitoring data to refine STMs.

\section{STEPS IN A REGIONAL SAMPLING AND SYNTHESIS STRATEGY}

The codevelopment of STMs and ecological sites seeks to link multiple sources of data and expert knowledge with soil and climate properties. The strategy we describe here is general and iterative; the steps should not be regarded as rigid. We start with informal ecological site and state concepts coupled to mapping. Concepts and maps are refined as information accumulates. Below, we outline the steps of a practical, but data-driven, approach with this idea in mind (summarized in Table 2).

\section{1) Creation of Initial Ecological Site Concepts and State-and- Transition Models}

Ecological Site Concepts. The development of ecological site concepts (i.e., specifying the identity and distinctive properties of ecological sites) occurs in tandem with development of STMs because each representative of an ecological site might be observed in a different state. Ecological site concepts, within an area of similar climate, are based on soil-geomorphic properties that affect the production, composition, or resilience of vegetation (e.g., Table 3). For example, Loamy Upland and Loamy Slopes have similar total production but differ in the dominant plant species in their respective reference states. These differences are related to differences in landscape position, slope, and hydrology. The STMs of both sites contain an eroded state characterized by partial loss of the A horizon, triggered by grass loss. The Gravelly Slopes site, on the other hand, does not feature an eroded state because the gravelly soil surface resists erosion. In general, distinct ecological sites are 
Table 2. A summary of steps for developing ecological site classes and state-and-transition models (STMs) within a project region.

\section{Step}

1. Develop initial ecological site concepts and STMS

2. Complete low-intensity survey

3. Hierarchically stratify the region

4. Complete medium-intensity survey

5. House data in database

6. Conduct exploratory analyses and tests of relationships

7. Refine ecological site and STM concepts

8. Complete high-intensity characterization and initiate monitoring
Tasks and issues to consider

a) Review general ecosystem models, conduct literature review, hold expert workshops/interviews

b) Specify functionally-important soil properties

c) Specify transient vs. persistent changes in vegetation

d) Consider scale and spatial context in transitions

a) Explore relationships among states, landforms, land uses, and soils across the project area

b) Refine strata for medium-intensity inventory

a) Assemble digital maps and remotely sensed imagery; link to low-intensity data

b) Delineate or recognize climate zones, soil-geomorphic systems, soil units (where soil maps absent or not of sufficient resolution), states, and key differences in patch structure

Sample vegetation, soils, and indicators across soil-geomorphic systems, ecological sites, and state strata/gradients and at many points.

Database allows soil, landform, and vegetation data to be related to one another

Use scatterplots, model building, quantile regression, and multivariate analysis to explore data and to test specific propositions derived from ecological sites and STMs

Based on analyses and synthesis of literature, modify ecological site classes, modify initial STMs, quantify characteristics of ecological sites and states

a) Generate statistical samples, especially for reference states, and collect precise information on vegetation and dynamic soil properties to establish characteristic values

b) Monitor points to document dynamics of the state justified when there are management-relevant differences in properties of the reference state or in the state's possible trajectories. The structural/functional distinctions among ecological sites should then be linked mechanistically to specific differences in soil-geomorphic properties. Thus, within a climate zone, ecological sites should be recognizable based solely on soil-geomorphic criteria (Table 3).

State-and-Transition Model Concepts. Concepts for STMs address three elements. First, they specify plant community properties, including composition, cover, and production of reference states that are chosen to best reflect the soil and climate-determined potential of the site (Sala et al. 1988). Increasingly, dynamic soil properties that affect plant resources and other functions (e.g., soil organic matter, soil structure, bulk density, infiltration rate, and water/nutrient-holding capacity) are described alongside plant attributes (see Tugel et al. 2005). Although the concept of a reference state is controversial because ecological potential is difficult to specify (Swetnam et al. 1999), we operationally define it as the state from which all other possible states (and associated functions) can be derived via lowintensity management. A "state" is conceived here as a dynamic regime (cf. Scheffer and Carpenter 2003), encompassing spatiotemporal variability denoted by multiple "community phases" occurring within the state (Stringham et al. 2003; Table 1). The general properties of the reference state are described (see below; Table 4), including the natural range of variation reflected in community phases (Landres et al. 1999). A reference community phase is designated that exhibits the structural and functional properties that are believed to impart resilience to the reference state. This phase provides a measurable, real-world benchmark for assessment and monitoring.

Variation in potential vegetation and dynamic soil properties cannot yet be modeled at landscape scales for a number of reasons (Peters et al. 2006). Thus, properties of the reference state or phase have been estimated from historically-observed conditions, extrapolations from similar ecological systems, and via measurements from areas deemed to be in a well-managed condition. Long-term climate change complicates the use of historical observations at a point in time to infer present-day potential (Brown and Bestelmeyer 2008). Unknown historical anthropogenic effects, such as extensive use of fire and agriculture by early Americans, further complicate interpretation of historical conditions (Mann 2006). Using existing site conditions to describe a set of reference conditions avoids these problems and allows direct measurement, even if current conditions deviate slightly from what might be regarded as potential. Existing sites also allow measurement of dynamic soil properties; they were not measured in historical efforts. Causes of deviation between existing and historical-based reference conditions can be described, when known.

Second, reference states are contrasted with alternative states and should specify distinct structure-function (or patternprocess) feedbacks (Scheffer and Carpenter 2003). For example, the transition from shrub savanna to a shrub-dominated state involves a change in two correlated feedbacks: reduced resource retention by grasses that allows resource transfer to shrubs and increasing resource heterogeneity (Schlesinger et al. 1990) and reduced fuel connectivity and fire frequencies that also favor shrubs (Table 4). Each state is defined based on a distinct structure-function feedback; these distinctions are usually of societal relevance. Concepts for states should also define the appropriate spatial scale for recognizing important structure-function feedbacks.

Third, STMs describe the triggers, drivers, and mechanisms of transition among states (see Westoby et al. 1989; Yates and Hobbs 1997; Bestelmeyer et al. 2003; Briske et al. 2008; Table 1). For example, one trigger for the transition from a shrub savanna to a shrub-dominated state is a high loss of grass basal cover due to mismanaged grazing during drought. Periods of high wind velocity and drought serve as important interacting drivers that are external to the local management 
Table 3. A draft ecological site key for the western limit of the Chihuahuan Desert ecoregion (US Department of Agriculture-Natural Resources Conservation Service [USDA-NRCS] major land resource area 41-1) in a zone of 400-500 mm mean annual precipitation, featuring aridic-ustic, thermic soils, in southeastern Arizona. Developed by the USDA-NRCS, Arizona. Terminology follows Soil Survey Staff 2006. See the USDA-NRCS Ecological Site Information System website to view particular ecological site descriptions (http://esis.sc.egov.usda.gov/Welcome/pgReportLocation. aspx?type=ESD).

I. Flooded (bottom position, flooded from the valley-side or over-bank)

A. Soils with a perennial high water table $(0-4.5 \mathrm{~m})$

1. Soils sandy and gravelly/cobbly without redoximorphic features

2. Soils loamy to clayey with redoximorphic features

B. Soils with seasonal (summer) water table at 1.5-6 m deep

C. Soils without a high water table (rely only on floodwater)
1. Soils sandy
2. Soils sandy loam to clay loam
3. Soils clayey (vertic)
1. Sandy Bottom
2. Cienega (wetland)
3. Loamy Bottom
4. Sandy Wash
5. Loamy Swales
6. Clayey Swales

II. Not flooded (upland position, receives only precipitation)

A. Slopes less than $15 \%$

1. Soils calcareous throughout

a. Soils shallow (less than $50 \mathrm{~cm}$ deep)

1. Soils with a carbonate-cemented hardpan

7. Limy Upland

b. Soils moderately deep to deep $(75-150 \mathrm{~cm})$

2. Soils with an argillic horizon

8. Loamy Upland, limy

2. Soils noncalcareous in upper $25 \mathrm{~cm}$

a. Soils shallow (less than $50 \mathrm{~cm}$ deep)

1. Soils underlain by granite, schist, rhyolite, sandstone bedrock

9. Granitic Upland

2. Soils underlain by basalt, andesite, shale bedrock

10. Volcanic Upland

b. Soils moderately deep to deep $(75-150 \mathrm{~cm})$

1. Soils without an argillic horizon

a. Soils loamy fine sand to sandy loam

2. Soils with an argillic horizon

a. Soils with sandy loam surface $10 \mathrm{~cm}$ or thicker

b. Soils with sandy loam surface less than $10 \mathrm{~cm}$

c. Soils with a loam surface

d. Soils with a clay loam surface (not vertic)

e. Soils with a clayey surface (vertic)

B. Slopes greater than $15 \%$

1. Soils shallow (less than $50 \mathrm{~cm}$ deep)

a. Soils calcareous throughout

1. Soils over limestone parent materials

2. Soils over limy conglomerate/fanglomerate

16. Limestone Hills

b. Soils noncalcareous

1. Soils over granite, schist, gneiss, rhyolite (acid igneous)

17. Conglomerate Hills

2. Soils over basalt, andesite, welded tuff (basic igneous)

17. Granitic Hills

18. Volcanic Hills

2. Soils moderately deep and deep $(75-150 \mathrm{~cm})$

a. Soils calcareous throughout

1. Soils dark colored $(10 \mathrm{YR}, 4 / 2)$ in the top $12 \mathrm{~cm}$

19. Limy Slopes

b. Soils noncalcareous in the upper $25 \mathrm{~cm}$

1. Soils sandy loam to clay loam

2. Soils clayey

20. Loamy Slopes

21. Clayey Slopes

system. The "at-risk" community phase within the reference and other states represents the consequences of triggers and drivers and an increased vulnerability to transition (Briske et al. 2008). For example, an at-risk phase for the scenario above would be characterized by a reduction of grass cover to a certain level and bare patches reaching a certain size. Autogenic recovery is still possible from this phase; therefore it is included in the reference state. Detailed description of the relationships between the at-risk phase, triggers, drivers, and feedbacks is a necessary precursor to communicate and evaluate model assumptions as well as to select useful indicators of thresholds.

General Ecosystem Models as a Starting Point. General ecosystem models (e.g., Miller 2005) developed for broad 
Table 4. Concepts for states and generic state names within Major Land Resource Area 42 in southern New Mexico. States are for ecological sites that have a significant woody plant component (>10\%) within a grassland matrix in the reference state (including Deep sand, Gravelly, Gravelly Loam, Gravelly Sand, Hills, Limestone Hills, Gyp Hills, Malpais). States are generally recognizable at scales of $0.1-1$ ha. The structure of the stateand-transition model, however, might differ among these ecological sites and not all states are represented in each site.

Concept for state (italics) followed by structural and feedback characteristics

1. Site near maximum productivity with full complement of historically-dominant species. Perennial grass cover dominant, woody plants largely scattered within a grass matrix or intermixed with grasses; some high-density shrub clusters. Grass cover facilitates infiltration, improves soil water availability, and stabilizes other resources, sustaining grass reproduction. Grass cover might also facilitate fire that limits shrub and tree populations.

2. Perennial grasses dominant, but historically-dominant species unlikely to recover without restoration. Historicallydominant grass species are absent or fragmented $(<10 \%)$, grazing-tolerant or disturbance-associated species might be dominant, productivity often patchy and low. Evidence of soil erosion. Low grass cover limits grass reproduction, resource retention, and/or stabilization of soil, limiting recovery of formerly dominant grasses.

3. Expanding woody plants are dominant but the distribution of remnant grass in woody plant interspaces suggests that competitive exclusion is incomplete and/or soil degradation is infrequent. Woody plants are dominant and dominant perennial grass species are restricted to discrete patches in shrub interspaces $(>10 \%$ cover of grass, with $>1 \%$ occurring in interspaces). Low grass cover allows preemption of resources by shrubs and redistribution of soil resources from interspaces to shrub patches. Reduced grass connectivity reduces likelihood of fire occurrence.

4. Biological activity is centered beneath expanding woody plants, perennial grasses away from woody plants are insignificant. Dominant perennial grass species entirely absent or as isolated relict patches ( $<10 \%$ cover). 95-100\% of existing grass cover occurs under shrubs. Evidence of interspace erosion/soil degradation is extensive, resource retention is low. Facilitation between shrubs and grasses sustains remaining grasses.

5. Perennial species absent or occur as isolated relict plants. Erosion extensive. Resource retention is very low.

6. The distribution of exotic species suggests that they can fill in the site over time, but do not govern ecosystem function of site. Exotic species (e.g., Eragrostis lehmaniana Nees) present or common ( $>5 \%$ cover). Fire and/or livestock grazing preferences favor growth and reproduction of exotic species relative to natives.

7. Exotic species are dominant and govern ecosystem function of site. Resources for growth and reproduction preempted by exotic species, fire can contribute to sustained dominance.
State name

Shrub/tree savanna (reference state)

Altered savanna

Shrub/tree-dominated

Expansion shrubland/woodland

Bare/annuals

Exotic-invaded

Exotic-dominated ecosystem types are useful starting points because they highlight dominant processes governing transitions. General models draw upon groups of mechanistic studies and quantitative modeling efforts. Specific examples include the effects of wind erosion and soil surface condition on arid, sandy soils (Okin et al. 2001) or fire-grazing interactions in piñon-juniper communities (Romme et al. 2008). General models sometimes indicate variation in soil and climate that should be captured in ecological site distinctions (e.g., piñon-juniper dynamics differ in shallow vs. deep soils) as well as the appropriate scale for recognizing states. For example, an STM might best apply to groups of intimately-linked soils and landscape features rather than individual soils (e.g., riparian zones and adjacent meadows; T. Stringham, personal communication, 2007; and see Pringle et al. 2006). Plant patches (i.e., discrete groupings of plants) that change rapidly in shape or spatial position (e.g., banded semiarid vegetation; Tongway et al. 2001) could be considered as components of a phase or state.

Next, initial STMs linked to preliminary ecological site concepts are developed based on literature that is combined with the local knowledge of land managers and scientists during group interviews at workshops (Bestelmeyer et al. 2003). In the United States, initial ecological site classifications might already exist within the project area or in similar areas to help focus discussions on particular soils. The general ecosystem models focus participants on ecological processes. In this way, STMs become holistic models that link site-specific details, often obtained from local knowledge, to general quantitative studies.
Synthesis of Multiple Data Sources and the Logic of Inventory. Transitions in rangelands have not been sufficiently documented; they take decades to unfold, and relevant processes have been missed where long-term data exist at all. We feel that an effective response to this problem is to assess 1) what changes have occurred in particular ecological sites, 2) whether assumptions about management and restorability are supported in studies of management actions, and 3) if contemporary patterns in vegetation and soils are consistent with explanations for ecosystem changes. With regard to 1), historical and longterm changes have been studied via repeat ground (Turner 1990; Hart and Laycock 1996) and aerial photography (e.g., Briggs et al. 2002) as well as spatially-referenced historical records such as General Land Office surveys (Andersen and Baker 2005). In some cases, repeat photography can be associated with recorded events, such as a fire or abrupt change in management, that provide additional information. With regard to 2), experimental investigations of degradation and restoration processes (e.g., Drewa et al. 2006) matched to ecological sites can be examined for consistency with presumed causes or constraints to change. Simulation models can also be used to link processes and ecological site properties to STMs (e.g., Peters 2002). With regard to 3), we argue that tests based on inventory sampling of current vegetation and soils provide a robust and practical means to evaluate STMs and ecological site concepts. Because inventory sampling does not depend on the availability of historical data and yields rapid results, we emphasize this avenue in the remainder of the paper. 
a)

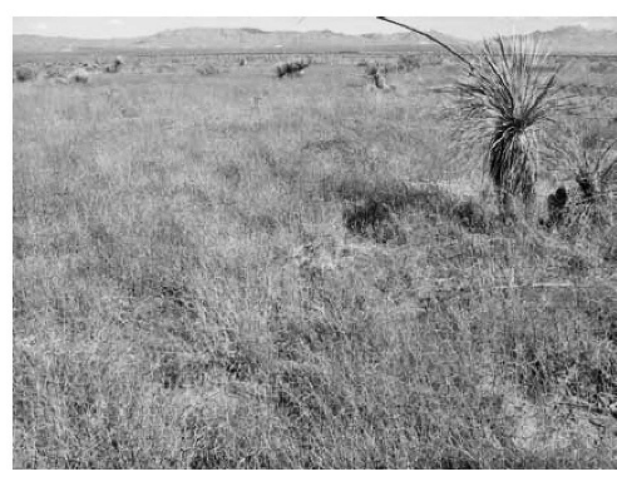

b)

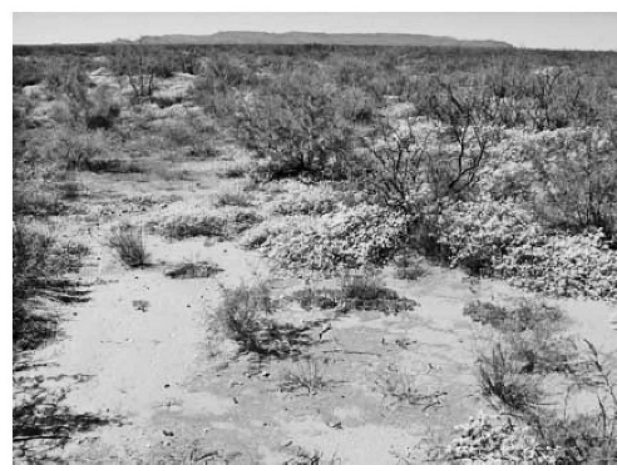

Figure 1. Alternative states of the same ecological site observed in different locations during a high-rainfall year. a, A grassland state on a coarse-loamy, mixed, superactive, thermic Typic Petroargid in southcentral New Mexico. The grass is black grama (Bouteloua eriopoda Torr.). b, A shrubland state with a similar soil profile dominated by mesquite (Prosopis glandulosa Torr.) and featuring eroded soils. Both soil profiles are correlated to the Shallow Sandy ecological site (Major Land resource Area 42.2), featuring loamy sand to sandy loam soils including an indurated calcic (caliche) horizon within $50 \mathrm{~cm}$.

Inventory data stratified to preliminary ecological sites and states allow us to test whether the presumed alternative states are observed on the same soil profiles and landscape positions (supporting their designation as true alternative states; see Fig. 1 for an example) or if they tend to be associated with distinct soil-geomorphic properties. If the latter is observed, we must ask if 1) the differences in vegetation reflect differences in ecological potential and therefore distinct reference conditions, or 2) the differences in vegetation reflect distinct trajectories of change for different ecological sites that historically shared the same vegetation. Distinguishing among these alternatives must involve other kinds of evidence, such as historical reconstructions and restoration experiments. Furthermore, we must be aware that a failure to measure relevant soil-landscape properties will produce misleading results. Nonetheless, inventory data provides an initial test of the validity of STMs.

\section{2) Three-Tier Sampling, Part 1: Low-Intensity Traverses}

With initial concepts for ecological sites and states established, the next objective is to produce an inventory dataset that couples plant and soil data in order to test the concepts. Based on practical considerations, we propose that this can be accomplished using three tiers of sampling that vary in intensity and that serve distinct purposes. The tiers generally parallel soil survey and mapping strategies of the US National Cooperative Soil Survey and include 1) low-intensity traverses used in initial, extensive reconnaissance to understand landform-soil-vegetation relationships and refine initial ecological site and state concepts; 2) medium-intensity inventory that is used to examine quantitative relationships between vegetation, soil horizon, and climate properties based on ecological site and state concepts; and 3) high-intensity characterization of soil and vegetation properties from a statistical sample of states within ecological sites. Dataforms we have used for each tier are available at the Ecological Site Description Resources webpage of the USDA-Agricultural Research Service Jornada Experimental Range website (http://usda-ars.nmsu.edu).

In this second step, low-intensity traverses are used to cover broad areas within a climate zone (e.g., Land Resource Unit) over which a set of ecological sites will apply. Traverses can occur in concert with Step 1, but are usefully undertaken after initial literature synthesis and workshops to guide traverses. The primary objective of this step is to cover as much land as possible in order to maximize the generality of concepts. Sampling occurs across the extent of the area, stratified by variation in climate gradients, geomorphology, and soils using digital maps (see Step 3 below). Randomly selected points are observed. Areas suspected to represent reference states, such as vegetation preserved in exclosures or cemeteries, are of particular interest and are targeted. Ecotones between states (due to soils or contrasting land uses) are also targeted. At sampling points, soil augers or shallow pits are dug to examine soil diagnostic horizons (e.g., depth to argillic, calcic, or rootrestrictive horizons) and classify the soil pedon to the series or higher taxonomic level (USDA-NRCS 2007). Soil samples generally are not collected. Vegetation states and community types within preliminary STMs are evaluated and additional states and communities might be discovered. Data are collected rapidly in order to obtain many samples. Although data sometimes are recorded informally in field notebooks, we recommend the collection of soil profile, state, and GPS data with a dataform. By recording data in rigorously-defined classes, traverse data can be used to evaluate relationships among vegetation and soil classes. Tentative soil map units (if they do not yet exist) and refined ecological site and state classes are generated.

\section{3) Development of a Spatial Hierarchy for Sampling}

Low-intensity traverses combined with digital data are used to create hierarchical stratification for medium-intensity inventory. The use of spatial hierarchies to structure inventory is not new (e.g., Cleland et al. 1997), but here we extend this idea to identify levels reflecting the cross-scale interactions driving transitions (Peters et al. 2006). As an example, management areas are nested within or cross climate zones that vary in precipitation. The geomorphology of the landscape determines how water is redistributed as well as the spatial arrangement of soils receiving that water. At a finer scale, the area encompasses mosaics of ecological sites that vary in water-holding capacity, nutrient availability, and plant-rooting environments. Plant communities vary within and among ecological sites due to the interaction of management history, plant traits, resource 


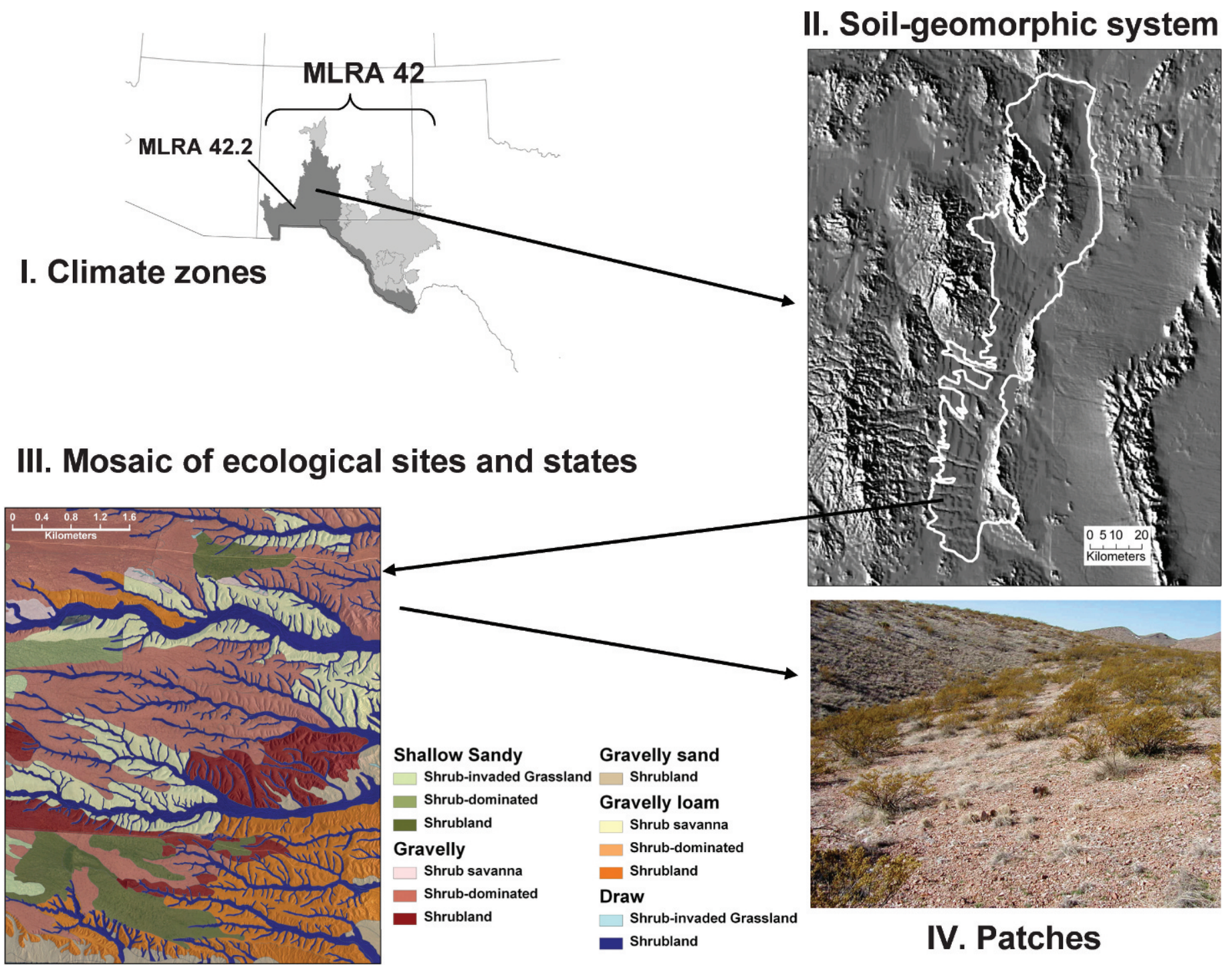

Figure 2. A spatial hierarchy used to guide inventory. I, The Major Land Resource Area (MLRA) 42 of the US Natural Resources Conservation Service and corresponding roughly to the Chihuahuan Desert ecoregion of the World Wildlife Fund. The dark shaded area is a subdivision, land resource unit MLRA 42.2 of the US Natural Resources Conservation Service. II, A soil-geomorphic system astride the Rio Grande River valley comprising relict piedmont, ballena, and inset fan landforms associated with the Pleistocene-Holocene entrenchment of the river. III, A mosaic of soils and ecological sites featuring Torriorthents in inset fans (Gravelly Sand) and complexes of Haplocalcids and Petrocalcids (Gravelly). Each ecological site is represented by a different primary color. Various states occur within these delineations, including shrub-savanna, shrub-dominated, and shrubland. States within sites are different shades of the primary color. IV, Patches of Bouteloua eriopoda grass occurring in the interspaces of Larrea tridentata shrubs, a characteristic of the shrub-dominated state in which restoration of grass cover is thought to be possible.

redistribution, and soil properties. At the finest scales, patches that occur within plant communities reflect plant-resource interactions (e.g., bare ground gaps that indicate reduced water capture by plant structures; Kuehl et al. 2001). Each level of the hierarchy interacts with others to determine states and transitions. For example, the loss of grass patches might trigger erosion that eventually forms gullies or moves a dunefield, but this might occur only on erosion-prone soils and within sufficiently arid landscapes. Consequently, the processes causing transitions among states need to be assessed at a variety of spatial scales. We propose that five hierarchical levels (Fig. 2) can be used to reflect these scales and help define the extent, stratification, and grain (or plot size) of inventory for vegetation and soils.
First, climate zones (e.g., ecoregions and subregions, Cleland et al. 1997; and MLRAs and Land Resource Units, McMahon et al. 2001) are regions that differ strongly in climate, plant environments, and soils, and thus they define the maximum extent of a single ecological site development effort (Table 1). For example, MLRA 42 (Fig. 2, panel I) differs from adjacent MLRAs in soil moisture or temperature regimes. Land Resource Units (e.g., MLRA 42.2 in Fig 2, panel I) are essentially "sub-MLRAs" that differentiate areas according to finer differences in climate that correspond to differences in species composition and production within similar vegetation formations (e.g., Sala et al. 1988). Sometimes these variations can be mapped, but in topographically complex areas, different climates can be intermingled (e.g., in different elevations and 
aspects). Samples should be distributed across these variations to test for their effects. Spatially-explicit climate data, especially the PRISM model within the United States (Daly et al. 2002) or CMORPH for the world (Joyce et al. 2004) can be used to delineate climate variations at coarse scales.

Second, areas within a climate zone are divided into distinct soil-geomorphic systems (SGSs) that describe the landscape context of ecological sites and states (Fig. 2, panel II). An SGS is a discrete land area with a characteristic spatial arrangement of ecological sites (and often states) that are linked by fluxes of materials, organisms and disturbances, soil-forming processes, and/or ecological processes. For example, along the valley border of the Rio Grande in southcentral New Mexico, mosaics of gravelly soil types with varying argillic and calcic horizon development are intermingled on relict piedmont landforms. Piedmont landforms are interspersed by gravelly washes, and this basic arrangement repeats throughout the SGS (Fig. 2, panel III). Thus, SGSs capture soil-landform relationships across multiple associated landforms (Birkeland 1999) and are similar to the concepts of the "soil-geomorphic template" (Monger and Bestelmeyer 2006), "landscape" in the sense of Zonneveld (1989) and Cleland et al. (1997), and the "ecosystem cluster" of Forman (1995). In the Basin and Range physiographic province of North America, for example, SGSs can be delineated as half-basins (see Peterson 1981; Gile and Grossman 1997; and especially West et al. 2005) that span an area bounded by north-south mountain crests and the midline of the basin floors and, perpendicular to this dimension, a region of similar combinations of parent materials. In this case, samples could be stratified based on landforms and slope components to understand the consequences of hydrological linkages. In an SGS defined by wind erosion and deposition, one might locate samples to characterize both sediment source areas and downwind depositional areas. Overall, it is important to recognize that representatives of an ecological site can vary in their landscape context across a region. SGSs highlight the varying context of sampling points and allow local measurements to be interpreted with respect to landscape linkages as well as local ecological site and state properties.

Third, ecological sites, considered as a spatial unit, occupy distinct soils and topographic positions within an SGS (similar to the land units of Cleland et al. 1997). Because ecological sites are linked to soil map unit components in the United States, ecological sites are sometimes combined in soil mapping units featuring associations, consociations, or complexes. Nonetheless, for the purposes of initial stratification, many soil map units can usefully be classified according to the spatially-dominant ecological site within them (Fig. 2, panel III) while recognizing that they are not necessarily homogeneous. Visual cues obtained in the field (e.g., surface soil color, gravel, slope) are used to stratify samples more precisely. Where soil surveys (e.g., http:// soildatamart.nrcs.usda.gov/) do not exist, areas occurring on different landform components are likely to feature different ecological sites and can be recognized prior to inventory via digital elevation models, satellite imagery, or topographic maps. Spatially-dominant or otherwise important ecological sites (socalled "benchmark ecological sites") within a region can be used to prioritize sampling efforts.

Fourth, states or phases are treated as spatial units by recognizing that different ecological site delineations, or even portions of individual delineations (Fig. 2, panel III), can occur in alternative states/phases. Vegetation maps based on standardized vegetation classifications available through some Gap analysis programs and other detailed mapping efforts (http:// www.natureserve.org/prodServices/ecomapping.jsp) can be used to infer possible states and phases. Patchiness, texture, and spectral differences related to differences in both ecological sites and alternative states can be recognized in globally-available high-resolution imagery (http://earth.google.com/) and Landsat imagery (http://worldwind.arc.nasa.gov). Automated image classification methods or manual mapping turn these data into map polygons reflecting preliminary ecological sites and states within them. Stratification can be made less explicit by simply specifying sampling points in patches that are suspected to reflect distinct sites and states.

Fifth, patches within a state should help define the size of the plot within which data are gathered. Patches can be expressed at different scales, depending on the processes of interest, ranging from fire effects at the scale of hectares (e.g., Fuhlendorf and Engle 2004) to mosaics of plants and bare soil caused by facilitation, erosion, and hydrological processes operating at the scale of meters (Bisigato and Bertiller 1997; Ares et al. 2003; Rietkerk et al. 2004; see Fig. 2, panel IV). Patchiness also helps to distinguish states and specify "at-risk" community phases within the reference state. Plots should be sized so that differences in patch structure related to differences in transition processes can be detected. In some ecological sites or SGSs, ground plots might be an impractical means to assess patchiness, and remotely sensed imagery is needed.

\section{4) Three-Tier Sampling, Part 2: Medium-Intensity Inventory}

In this step, samples are stratified by variations of interest recognized via traverses and geospatial data in order to test concepts or hypotheses. For example, one might ask whether the distribution of a state throughout a Land Resource Unit, or across a sharp ecotone at a local scale, is related to land-use history, soil variation, or climate. Samples can be carefully stratified across multiple gradients in order to disentangle the effects of moderately correlated variables. In general, sampling strategies are designed to investigate the interrelationships of ecological sites, states, and community phases (e.g., Miller et al. 2001; Bestelmeyer et al. 2006). These data constitute the bulk of quantitative data used to test ecological site and state classes (see Example below) as well as to define mapping units.

Simple soil pedon descriptions should be sufficient to distinguish key soil characteristics used to identify ecological sites. Sampling with soil augers or shallow (e.g., $1 \mathrm{~m}$ ) soil pits (Schoeneberger et al. 2002) is usually appropriate. The depth of sampling needed to distinguish important soil attributes depends on soil and climate. Soils that require deeper observations are those in more humid regions as well as coarser and deeper soils (see Gile et al. 1998). Ecologically important soil attributes are observed in situ (e.g., soil horizons, soil structure, rock fragments) and samples of horizons are gathered for possible laboratory analysis (e.g., soil texture, calcium carbonate content, salinity/sodicity). Vegetation and soil surface data are gathered using a rapid protocol featuring ocular estimation of vegetation cover and nominal indicators. Alternatively, high intensity characteriza- 
tion methods (see Step 8 below) might be preferred if ocular estimation is deemed incapable of capturing relevant information about states or phases, but this option increases the time spent per sample. It is useful if the combined vegetation and soil protocol maintains a similar pace between soil and vegetation sampling (if performed by different personnel), thereby increasing efficiency and sample size.

In the northern Chihuahuan Desert and Colorado Plateau, the protocol has been performed in $20 \times 20 \mathrm{~m}$ square plots where the center of the plot is defined by the soil sample. This plot size was selected to be large enough to represent patchiness in the plant communities and soil surface properties (e.g., rare grass species and bare ground patterns) in the study areas we tested, but small enough to link the soil characterized in the center of the plot to the surrounding plant community. Plot sizes can be adjusted depending on variations in vegetation and soil pattern.

Ocular estimation provides a complete census of species in the plot and provides rough, relative cover estimates. Both can be useful in defining states based on remnant vegetation (e.g., Briske et al. 2006). Simple pattern-based indicators assist in rapidly characterizing soil surface conditions (see the Ecological Site Description Resources webpage of the Jornada Experimental Range [Pedoderm Indicators] and also Tongway and Hindley 2004).

\section{5) Database Development}

A practical limitation to relating vegetation and soil data has been the lack of a database to house plot data on vegetation and soil properties from identical, georeferenced locations. For example, the National Cooperative Soil Survey and the USDANRCS have separate databases for point soil data and ecological site inventory data (i.e., the National Soil Information System and the Ecological Site Information System, respectively). Currently there is no mechanism to link these databases. A personal database was developed in Microsoft Access that links plant and soil inventory and monitoring data and is freely available (see Monitoring and Assessment webpage, Rangeland database; http://usda-ars.nmsu.edu). Queries generate tables that link vegetation and soil variables at points for quantitative analysis. Although the data underlying currently-available ESD reports are generally unavailable, publically-accessible point databases would enable broadened participation by the science and management communities in improving ecological sites and STMs.

\section{6) Data Analysis}

In examining the medium-intensity inventory data, it is useful to view the occurrence of alternative states as a combined function of inherent differences in soils and variation in landuse effects. The magnitude of these two effects often cannot be easily disentangled, but we can ask how plant species relate to one another and how soil and climate affect plant distributions (e.g., Jacobs et al. 2008). Researchers usually take widely varying approaches to these kinds of questions with different statistical tools and varying levels of sophistication. The data produced by the sampling approaches described here most easily lend themselves to simple scatterplots in two or three dimensions. Such plots can be used to evaluate the strength of correlations or to look for discontinuities across gradients. The multimodel inference approach of Burnham and Anderson (2002) allows a rigorous evaluation of the evidence for alternative statistical models and the importance of particular factors. The development of STMs is especially well-suited to specifying and testing alternative models about the existence and origins of alternative states.

A drawback of traditional linear models, however, is their emphasis on mean responses. Alternatively, quantile regression offers the ability to examine relationships at other parts of the response distribution, most notably at the extreme quantiles (i.e., $5-10 \%$ and $90-95 \%$; Cade and Noon 2003). The distribution of a response variable in a cloud of data points in $\mathrm{x}-\mathrm{y}$ space is a useful basis for ecological site development because ecological sites explicitly acknowledge that the mean relationship between a predictor variable (e.g., soil depth) and a response variable (e.g., grass cover) at ecological potential might be obscured by local land use or climate history and transitions to alternative states.

Thus, relationships at the upper and lower boundaries of a data cloud might reveal fundamental, ecologically limiting factors (Scharf et al. 1998; Cade and Noon 2003). The distribution of points within these boundaries reflects a variety of other (often unmeasured) effects, such as disturbance history. Thus, for example, we can assert that those points near the upper boundary of a native vegetation productivityenvironment relationship reflect, as best we can measure it in inventory, reference conditions. All else being equal, data points falling far below this upper boundary represent extreme departures from the reference and could represent postthreshold states. If the points were from a broad-scale inventory, the distribution of points in various quantiles below the upper limit could reflect the dominant processes at work in a landscape (e.g., Cade and Noon 2003). Although a number of ideas and observations must be included to support such assertions, we suggest that quantile regression is an especially useful tool to develop ecological sites.

\section{7) Refine State-and-Transition Model and Ecological Site Concepts}

At this stage, analysis and interpretation of medium-intensity data are used to revisit the initial concepts. Additional ecological sites might be recognized or two sites may be fused together. STMs might be modified to recognize that, for example, some plant communities formerly considered as alternative states actually reflect reference conditions of another ecological site (Bestelmeyer et al. 2003). Medium-intensity data can be used to distinguish quantitatively ecological sites and states in ESDs, considering the range of variation observed in the samples. Statistical patterns in inventory data should suggest hypotheses regarding the temporal relationships among states and mechanisms of transition that can be tested experimentally.

\section{8) Three-Tier Sampling, Part 3: High-Intensity Characterization and Monitoring}

Once concepts of ecological sites and states are well-established, a statistical random sample of states are characterized in detail and monitored. Intensive measurements can be used to understand how states function by quantifying (and testing) the relationships among properties involved in key feedbacks 
asserted in STMs, such as plant cover and soil surface properties. Comparisons of the properties of alternative states based on a statistical sample are used to communicate unambiguously the criteria for states, especially for the reference state. Monitoring is used to characterize temporal processes and to test statements about autogenic recovery that are asserted in STMs.

Recommended function-based measurements include linepoint intercept transects for soil surface cover, basal cover, and canopy cover, as well as transects for basal gap intercept (Herrick et al. 2005). These measurements provide precise information about both plant composition and the influence of plants on soils and surface hydrology. A census of important rare species not recorded on the line-point intercept transects should be performed. Belt transects (or similar technique) should be used for systems threatened by colonization of woody or invasive species. Dynamic soil property measurements are made to a depth of $30-60 \mathrm{~cm}$ and can include soil aggregate stability, bulk density, and percentage of soil organic matter (SOM) or individual SOM fractions in the upper soil horizons (see Tugel et al. 2005). Finally, production estimates are gathered from within the plot following common techniques (Herrick et al. 2005). Irrespective of these general recommendations, it is important to match the measurements gathered to the structures and processes believed to govern states and transitions.

Once ecological sites, states, and phases are clearly defined, data from a variety of sources can be linked directly to them. In this way, ecological sites and STMs can be used as data libraries that link information about ecological properties and dynamics to land units. This information can include biodiversity, carbon sequestration potential, long-term trends in net primary productivity, and livestock grazing uses. Once this information is linked to STMs in databases, maps of states can serve as a means to represent spatially the existing and possible levels of multiple ecosystem services.

\section{EXAMPLE: TESTING AND REFINING STATE AND ECOLOGICAL SITE CONCEPTS}

We provide a simplified example to illustrate how inferences can be drawn from inventory data collected following our approach. First, we used existing soil surveys, ESDs, and lowintensity traverses to delineate a "valley-border ballena" soilgeomorphic system (ca. $4500 \mathrm{~km}^{2}$ ) for focused study within the Chihuahuan Desert ecoregion, in south-central New Mexico, USA (Fig. 2, panel II). The characteristic landforms of the area are relict fan piedmonts, ballenas, and inset fans (sensu Peterson 1981). Dominant, mapped soils on relict landforms in this area are currently associated with a single ecological site (Gravelly; see USDA-NRCS 2002). Second, we used the conceptual state-and-transition model developed via interviews and literature to consider hypotheses regarding the encroachment of creosotebush (Larrea tridentata [DC.] Coville) into former perennial shrub-savannas (grasses are mostly black grama, Bouteloua eriopoda [Torr.] Torr. and bush muhly, Mublenbergia porteri Scribn. ex Beal.). The lowintensity field surveys revealed that many areas currently exist in the historical (reference) shrub-savanna state, whereas others are in a degraded, shrubland state within the same ecological site, on similar landscape positions, and sometimes within the same management unit. Because the area is located on relict landforms that are hydrologically disconnected from adjacent landforms, the effects of landscape context need not be considered. So we asked, does the occurrence of different states relate consistently to a soil horizon or climate property (suggesting that the putative states might in fact occur on different ecological sites) or are the states unrelated to soil/ landform properties (suggesting that they are true alternative states reflecting spatial variation in historical events)?

We tested these alternatives by sampling vegetation and soils in 78 plots located across the valley-border ballena SGS. Sampling followed a combination of medium- and highintensity procedures described earlier (including line-point intercept transects for vegetation cover in $20 \times 20 \mathrm{~m}$ plots, 10 lines/plot, $2 \mathrm{~m}$ between lines, $1 \mathrm{~m}$ between points, and soil pits to $75 \mathrm{~cm}$ to characterize soil horizons). We used quantile regression (BLOSSOM software; Cade and Richards 2005) to describe relationships between response variables and key explanatory variables. Significance is based on nonparametric quantile rankscore tests with 10000 permutations.

Our assessment of dominant explanatory variables revealed that perennial grass canopy cover had a negative exponential relationship with Larrea canopy cover at the 50th (conditional median) quantile (asymptotic rank score test $=8.72$; $P=0.003$ ), and increasing Larrea placed a significant, decreasing upper bound on cover of perennial grasses at the 90th quantile (asymptotic rank score test $=7.86 ; \quad P=0.005$; Fig. 3a). Beyond ca. 12\% Larrea cover, grass cover is never observed to be higher than ca. $15 \%$. This observation is consistent with alternative states. Points falling far below the upper bound at low Larrea cover values might represent plant communities at risk of persistent degradation, following the idea that management-induced low grass cover facilitates shrub encroachment and soil degradation. These would be ideal points for long-term monitoring. The points that define the upper bound, on the other hand, might represent the current potential for perennial grass cover in the SGS.

The question remains, what governs Larrea cover? We found a significant and strong relationship between Larrea cover and $\mathrm{CaCO}_{3}$ (\% by volume of the soil fraction) in the first B soil horizon (see Bestelmeyer et al. 2006 for laboratory technique) at the 50th quantile (asymptotic rank score test $=29.3$; $P<0.0001$; Fig 3b). Furthermore, increasing $\mathrm{CaCO}_{3}$ placed a significant, increasing lower limit to Larrea cover at the 10th quantile (asymptotic rank score test $=5.99 ; P=0.01$ ). Thus, when $\mathrm{CaCO}_{3}$ content of the upper B horizon was high (e.g., $>20 \%$ ) Larrea cover was never low. Although we currently have not tested any mechanism that explains this relationship, we conclude that Larrea cover is governed by $\mathrm{CaCO}_{3}$ content, or a soil property that is strongly correlated with $\mathrm{CaCO}_{3}$ content, such as phosphorus availability. Because minimum Larrea cover is strongly correlated with a soil property that is independent of land-use history (Gile 1961), there is support for recognizing an additional ecological site, "calcareous gravelly," that would feature a greater propensity for shrub dominance and low grass cover.

Additionally, we ocularly estimated a simple indicator of vegetation patch spatial pattern during the inventory: the 

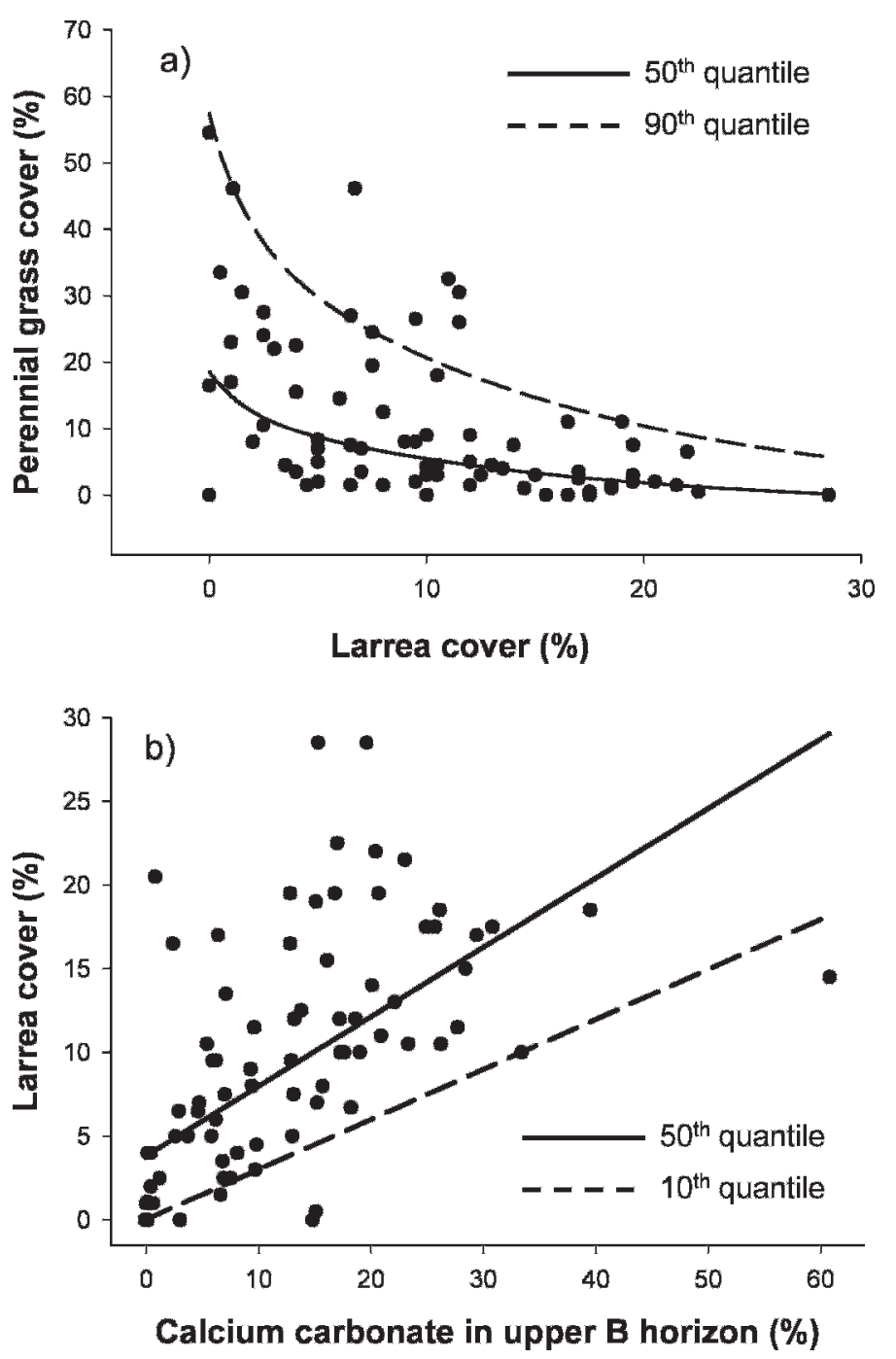

Figure 3. a, Relationship between percent canopy cover of Larrea tridentata and perennial grass cover in the valley border ballena soilgeomorphic system. The solid line is fit to a negative binomial function for the 50th quantile and the dashed line to the 90th quantile. See text. b, Relationship between percent calcium carbonate in the shallowest B soil horizon (e.g., Btk1) and percent canopy cover of Larrea tridentata. The solid line is fit to a linear function for the 50th quantile and the dashed line to the 10th quantile.

percent of the perennial grass cover that was restricted to soil mounds beneath the Larrea shrubs. Values range from 100\% (all grasses present occupy shrub mounds) to zero (grasses are not found on shrub mounds). High values of this indicator suggest that soil interspaces between shrubs might be degraded and that the site will not recover much grass cover were the shrubs to be removed via intensive manipulations. At low cover values of perennial grasses, an even distribution of those grasses (low to moderate indicator values) raises hope that the shrub interspaces are capable of supporting additional grasses with favorable management. The inventory data indicate that both high and low indicator values occur at similar levels of perennial grass cover (Fig. 4). These observations suggest that patchiness indicators might be useful for defining alternative states and that cover values alone might not be sufficient to

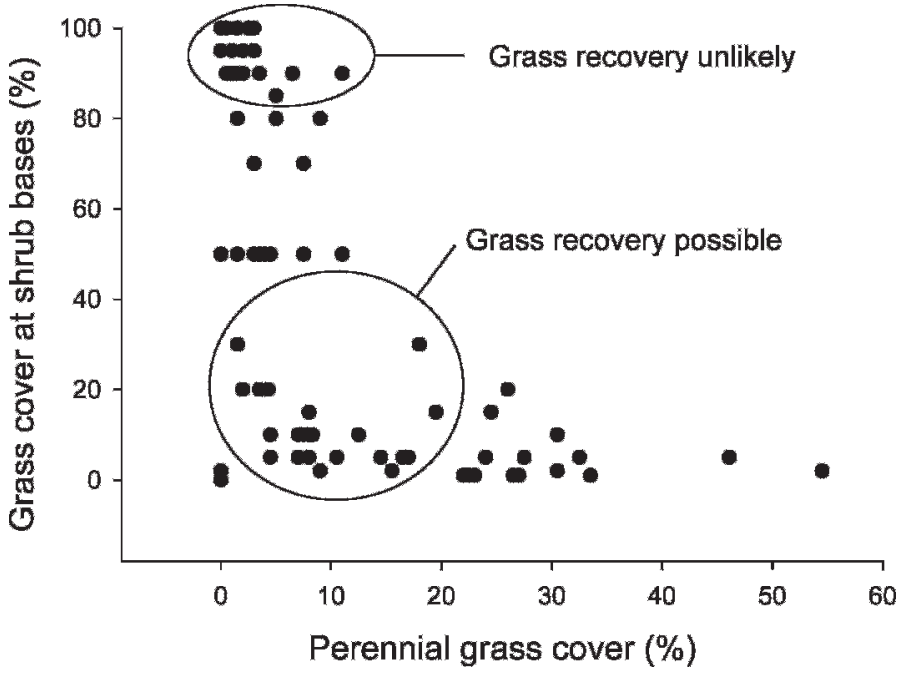

Figure 4. The relationship between the visually estimated percent grass cover in a $400 \mathrm{~m}^{2}$ plot that was under shrub canopies and percent canopy cover of grasses recorded in the valley border ballena soilgeomorphic system.

distinguish states. The predictive value of the indicator is being tested in restoration experiments.

The STM for the Gravelly ecological site now draws its structure from a variety of information sources (Fig. 5). First, inventory data suggest that at least two ecological sites should be recognized; sites with high levels of calcium carbonate in the upper B horizon are more prone to shrub dominance. General Land Office Surveys (from 1858) establish that areas currently occupied by shrubland states (on both high- and low-carbonate soils) were once grasslands or savannas (Gibbens et al. 2005); inventory indicates that these reference conditions are preserved in some locations. Repeat photography before and after reduction of stocking densities documents resilience of the reference state over $28 \mathrm{yr}$ when it was heavily grazed (but when grasses remained in interspaces). Repeat photography also documents transitions to a shrub-dominated state although the causes are unknown and novel shrub species (Acacia neovernicosa Isely) are involved. Long-term monitoring of shrub-control experiments in shrub-dominated states of Gravelly soils (Havstad et al. 1999) indicates that black grama recolonization of shrub interspaces can take many decades; the reference state might never be recovered (and see Perkins et al. 2006). Monitoring and repeat photography suggest that the shrubland state can be persistent and not experience periodic recruitment of bunchgrasses, in contrast with the shrub-dominated state. This example illustrates the value in combining inventory, historical documentation, expert knowledge, and monitoring experiments to provide evidence for the structure of STMs and to illustrate where additional data are needed. Any individual data source can address only specific elements of model structure.

\section{MANAGEMENT IMPLICATIONS}

Although admirable progress has been made to uncover general factors regulating ecosystem function (e.g., Reynolds et al. 


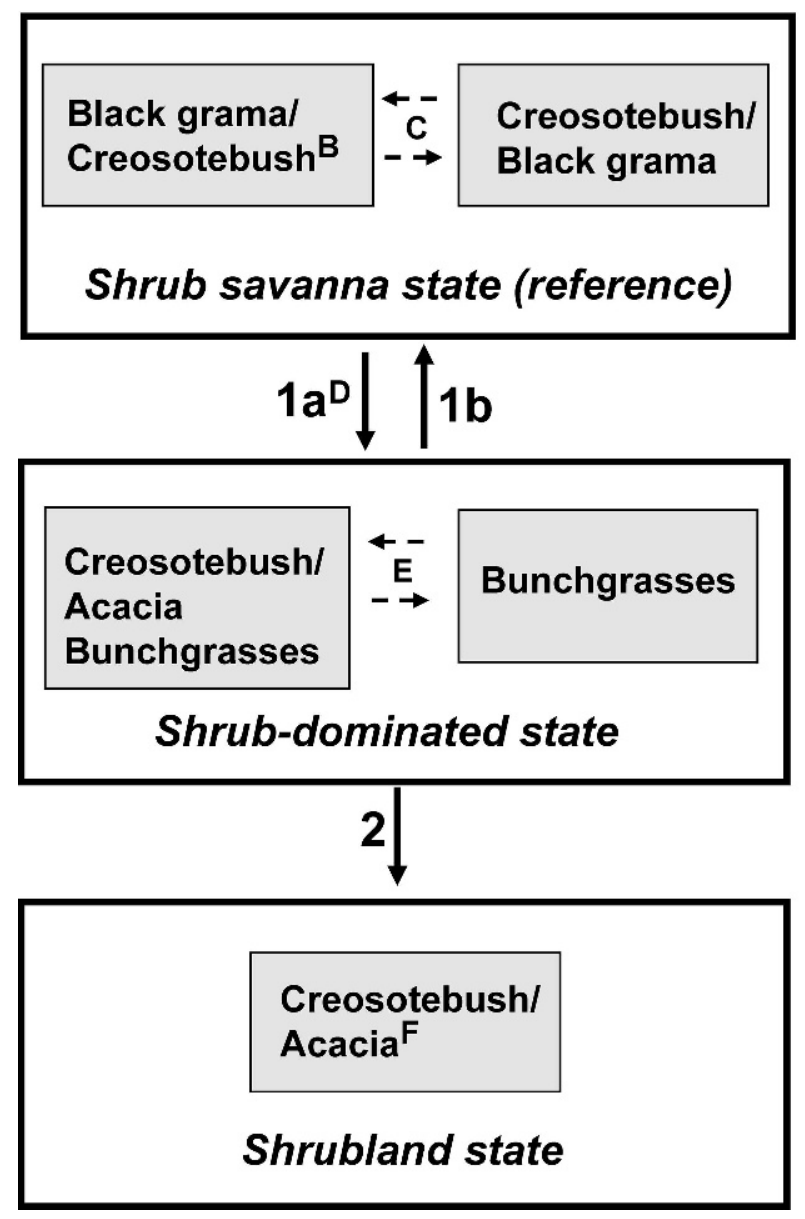

\section{Sources of data for elements of ESD and model}

A. Inventory of vegetation/soils suggests carbonatic soils and shallow petrocalcids belong to a different ecological site.

\section{B. Georeferenced General Land Office Survey data indicate a savanna reference state; inventory confirms existence.}
C. Repeat photography of a site with low grazing intensity since 1970 indicates recovery of reference phase in $28 \mathrm{y}$.

\section{Repeat photography of two sites suggests that Acacia spp. are important invaders since 1970.}
E. Shrub control experiment suggests that black grama does not reestablish dominance in $56 \mathrm{y}$, but does increase in cover.

\section{F. Monitoring indicates stability of this phase; inventory data indicate that shrubland state can be found on similar soils as reference state.}

Figure 5. A simplified state-and-transition model for the Gravelly ecological site in MLRA 42.2 of southern New Mexico. Sources of data used to support specific elements of the model are referenced to superscripts in the diagram. Transition 1a, Episodes of heavy grazing and drought associated with shrub expansion; 1b, Shrub control or fire alongside prescribed grazing; 2, Persistent reduction in grasses, erosion, soil degradation.

2004), we often have little understanding of how landscape heterogeneity mediates ecological function and resilience. The scientific void is reflected to varying degrees in many land classifications and STMs. Thus, much of the scientific basis for these tools will need to be built from the ground up. The strategy we outlined provides a practical approach to science support by integrating spatial data and expert knowledge with new and existing field data.

The strategy begins with a clear articulation of concepts based on expert knowledge, literature, and rapid field observations across the focal climate zone. Field observations are combined with geospatial data to stratify the region at multiple scales. Medium-intensity inventory based on the stratification is used to test alternative hypotheses about the properties of ecological sites and STMs. The data are housed in a database designed to relate vegetation, soils, and indicators. Analysis of inventory data asks, for example, whether there is evidence for alternative states and whether putative states should be viewed as alternatives for a particular ecological site. Based on the analysis, concepts for ecological sites and STMs are reconsidered. High-intensity sampling and monitoring is then used to characterize the ecological functions of states. The development of quantitative support for an STM and ecological site should not simply be used to legitimize the informal concepts of the researcher. Inventory and other data that are collected as part of our strategy can be used to discover previously unrecognized relationships and fundamentally change our perception of landscape function.

Implementation of our strategy would benefit from new training opportunities and collaborative activities that bridge rangeland and forest ecology to pedology, geomorphology, and landscape ecology. Ecologists who are well-versed in soil science are rare and often learn the relationship between plant ecology and soil science informally and "on the job" with their mentors. Improved interdisciplinary collaboration would also have clear benefits. Ecological site development works best if there is iterative feedback between ecologists and soil scientists in creating ecological site concepts and designing maps. New university curricula in natural resources and university-interagency institutes, coupled to funding opportunities, could provide improved training and coordination activities. Societies already invest substantial resources in monitoring, regulation, and restoration activities; a similar investment in land classification and STM concepts would help ensure that these resources are used effectively. 


\section{ACKNOWLEDGMENTS}

Phil Heilman, Curtis Talbot, Bob Nowak, Michael Carpinelli, and Dave Briske provided valuable comments. Phil Smith, David Trujillo, Caiti Steele, Steven Yanoff, and Laura Burkett were instrumental in refining many of the ideas described here.

\section{LITERATURE CITED}

Andersen, M. D., And W. L. Baker. 2005. Reconstructing landscape-scale tree invasion using survey notes in the Medicine Bow Mountains, Wyoming, USA. Landscape Ecology 21:243-258.

Ares, J., H. Del Valle, and A. Bisigato. 2003. Detection of process-related changes in plant patterns at extended spatial scales during early dryland desertification. Global Change Biology 9:1643-1659.

Barbour, R. J., M. A. Hemstrom, and J. L. Hayes. 2007. The Interior Northwest Landscape Analysis System: a step toward understanding integrated landscape analysis. Landscape and Urban Planning 80:333-344.

Bestelmeyer, B. T., J. R. Brown, K. M. Havstad, G. Chavez, R. Alexander, and J. E. HerRick. 2003. Development and use of state-and-transition models for rangelands. Journal of Range Management 56:114-126.

Bestelmeyer, B. T., J. E. Herrick, J. R. Brown, D. A. Trujillo, and K. M. Havstad. 2004. Land management in the American Southwest: a state-and-transition approach to ecosystem complexity. Environmental Management 34:38-51.

Bestelmeyer, B. T., J. P. Ward, and K. M. Havstad. 2006. Soil-geomorphic heterogeneity governs patchy vegetation dynamics at an arid ecotone. Ecology 87:963-973.

Birkeland, P. W. 1999. Soils and geomorphology. 3rd ed. New York, NY, USA: Oxford University Press. $430 \mathrm{p}$.

Bisigato, A. J., AND M. B. Bertiller. 1997. Grazing effects on patchy dryland vegetation in northern Patagonia. Journal of Arid Environments 36:639-653.

Briggs, J. M., G. A. HoCh, And L. C. Johnson. 2002. Assessing the rate, mechanisms, and consequences of the conversion of tallgrass prairie to Juniperus virginiana forest. Ecosystems 5:578-586.

Briske, D. D., B. T. Bestelmeyer, T. K. Stringham, and P. L. Shaver. 2008. Recommendations for development of resilience-based state-and-transition models. Rangeland Ecology and Management 61:359-367.

Briske, D. D., S. D. Fuhlendorf, and F. E. Smeins. 2006. A unified framework for assessment and application of ecological thresholds. Rangeland Ecology and Management 59:225-236.

Brown, J. R., and B. T. Bestelmeyer. 2008. Resolving critical issues for the development of ecological site descriptions: summary of a symposium. Rangelands 30:16-18.

Burnham, K. P., and D. R. Anderson. 2002. Model selection and multimodel inference: a practical information-theoretic approach. 2nd ed. New York, NY, USA: Springer-Verlag. 488 p.

Buxbaum, C. A. Z., and K. Vanderbilt. 2007. Soil heterogeneity and the distribution of desert and steppe plant species across a desert-grassland ecotone. Journal of Arid Environments 69:617-632.

Cade, B. S., And B. R. Noon. 2003. A gentle introduction to quantile regression for ecologists. Frontiers in Ecology and Environment 1:412-420.

CAdE, B. S., and J. D. Richards. 2005. User manual for BLOSSOM statistical software. Fort Collins, CO, USA: US Geological Survey, Midcontinent Ecological Science Center. $124 \mathrm{p}$.

Carpenter, S. R., and W. A. Brock. 2006. Rising variance: a leading indicator of ecological transition. Ecology Letters 9:308-315.

Christian, C. S. 1958. The concept of land units and land systems. Proceedings of the Ninth Pacific Science Congress 20:74-81.

Cleland, D. T., R. E. Avers, W. H. McNab, M. E. Jensen, R. G. Balley, T. King, and W. E. RusseLl. 1997. National hierarchical framework of ecological units. In: M. S. Boyce and A. Haney [EDS.]. Ecosystem management: applications for sustainable forest and wildlife resources. New Haven, CT, USA: Yale University Press. p. 181-200.

Creque, J. A., S. D. Bassett, and N. E. West. 1999. Viewpoint: Delineating ecological sites. Journal of Range Management 52:546-549.
Daly, C., W. P. Gibson, G. H. Taylor, G. L. Johnson, and P. Pasteris. 2002. A knowledge-based approach to the statistical mapping of climate. Climate Research 22:99-113.

Drewa, P. B., D. P. C. Peters, and K. M. Havstad. 2006. Population and clonal level responses of a perennial grass following fire in the northern Chihuahuan Desert. Oecologia 150:29-39.

DyksteRHuis, E. J. 1958. Ecological principles in range evaluation. Botanical Review 24:253-272.

Fancy, S. G., J. E. Gross, and S. L. Carter. In press. Monitoring the condition of natural resources in U.S. national parks. Environmental Monitoring and Assessment.

Forbis, T. A., L. Provencher, L. Frid, and G. Medlyn. 2006. Great Basin Land Management planning using ecological modeling. Environmental Management 38:62-83.

Forman, R. T. T. 1995. Land mosaics: the ecology of landscapes and regions. New York, NY, USA: Cambridge University Press. 632 p.

Friedel, M. H. 1991. Range condition assessment and the concept of thresholds: a viewpoint. Journal of Range Management 44:422-426.

Fuhlendorf, S. D., AND D. M. Engle. 2004. Application of the fire-grazing interaction to restore a shifting mosaic on tallgrass prairie. Journal of Applied Ecology 41:604-614.

Funlendorf, S. D., and F. E. Smeins. 1998. The influence of soil depth on plant species response to grazing within a semi-arid savanna. Plant Ecology 138:89-96.

Gallant, A. L., T. R. Loveland, T. L. Sohl, and D. E. Napton. In press. Using an ecoregion framework to analyze land-cover and land-use dynamics. Environmental Management.

Gibbens, R. P., R. P. McNeely, K. M. Havstad, R. F. Beck, and B. Nolen. 2005. Vegetation change in the Jornada Basin from 1858 to 1998. Journal Arid Environments 61:651-668.

GILE, L. H. 1961. A classification of Ca horizons in soils of a desert region, Dona Ana County, New Mexico. Soil Science Society of America Proceedings 25:52-61.

Gile, L. H., R. P. Gibbens, and J. M. Lenz. 1998. Soil-induced variability in root systems of creosotebush (Larrea tridentata) and tarbush (Flourensia cernua). Journal of Arid Environments 39:57-78.

Gile, L. H., And R. B. Grossman. 1997. The desert project soil monograph. Lincoln, NE, USA: Natural Resources Conservation Service, USDA National Soil Survey Center. $984 p$.

HART, R. H., AND W. L. LAYCocK. 1996. Repeat photography on range and forest lands in the western United States. Journal of Range Management 49: 60-67.

Havstad, K. M., R. P. Gibbens, C. A. Knorr, and L. W. Murray. 1999. Long-term influences of shrub removal and lagomorph exclusion on Chihuahuan Desert vegetation dynamics. Journal of Arid Environments 42:155-166.

Herrick, J. E., B. T. Bestelmeyer, S. R. Archer, A. J. Tugel, and J. R. Brown. 2006. An integrated framework for science-based arid land management. Journal of Arid Environments 65:319-335.

Herrick, J. E., J. W. Van Zee, K. M. Havstad, and W. G. Whitford. 2005. Monitoring manual for grassland, shrubland and savanna ecosystems. Volume 1. Quick start. Tucson, AZ, USA: University of Arizona Press. 36 p.

HobBs, R. J., AND S. Mclntyre. 2005. Categorizing Australian landscapes as an aid to assessing the generality of landscape management guidelines. Global Ecology and Biogeography 14:1-15.

Hughes, R. F., S. R. Archer, G. P. Asner, C. A. Wessman, C. McMurtry, J. Nelson, and R. J. ANSLEY. 2006. Changes in aboveground primary production and carbon and nitrogen pools accompanying woody plant encroachment in a temperate savanna. Global Change Biology 12:1733-1747.

JaCoBs, B. F., W. H. Romme, and C. D. Allen. 2008. Mapping "old" vs. "young" pinon-juniper stands with a predictive topo-climatic model. Ecological Applications 18:1627-1641.

Joyce, R. J., J. E. Janowiak, P. A. Arkin, And P. Xie. 2004. CMORPH: a method that produces global precipitation estimates from passive microwave and infrared data at high spatial and temporal resolution. Journal of Hydrometeorology 5:487-503. 
KIng, E. G., AND R. J. HoBBs. 2006. Identifying linkages among conceptual models of ecosystem degradation and restoration: towards an integrative framework. Restoration Ecology 14:369-378.

Kuehl, R. 0., M. P. McClaran, and J. Van Zee. 2001. Detecting fragmentation of cover with line intercept measures in simulations of desert grassland conditions. Journal of Range Management 54:61-66.

Kunst, C., E. Monti, H. Perez, and J. Godor. 2006. Assessment of the rangelands of southwestern Santiago del Estero, Argentina, for grazing management and research. Journal of Environmental Management 80:248-265.

Landres, P. B., P. Morgan, and F. J. Swanson. 1999. Overview of the use of natural variability concepts in managing ecological systems. Ecological Applications 9:1179-1188.

Mann, C. C. 2006. 1491: new revelations of the Americas before Columbus. New York, NY, USA: Vintage Books. $541 \mathrm{p}$.

McAuLlfFE, J. R. 1994. Landscape evolution, soil formation, and ecological patterns and processes in Sonoran desert bajadas. Ecological Monographs 64:111-148.

McAuliffe, J. R., E. P. Hamerlynck, and M. C. Eppes. 2007. Landscape dynamics fostering the development and persistence of long-lived creosotebush (Larrea tridentata) clones in the Mojave Desert. Journal of Arid Environments 69:96-126.

McMahon, G., S. M. Gregonis, S. W. Walton, J. M. Omernik, T. D. Thorson, J. A. Freeouf, A. H. Rorick, And J. E. Keys. 2001. Developing a spatial framework of common ecological regions for the conterminous United States. Environmental Management 28:293-316.

Miller, D., S. Archer, S. F. Zitzer, and M. T. Longnecker. 2001. Annual rainfall, topoedaphic heterogeneity, and growth of an arid land tree (Prosopis glandulosa). Journal of Arid Environments 48:23-33.

MilleR, M. E. 2005. The structure and functioning of dryland ecosystems: conceptual models to inform long-term ecological monitoring. Reston, VA, USA: US Geological Survey Scientific Investigations Report 2005-5197. 74 p.

Monger, H. C., and B. T. Bestelmeyer. 2006. The soil-geomorphic template and biotic change in deserts. Journal of Arid Environments 65:207-218.

Okin, G. S., B. Murray, and W. H. Schlesinger. 2001. Degradation of sandy arid shrubland environments: observations, process modeling, and management implications. Journal of Arid Environments 47:123-144.

Perkins, S. R., K. C. McDaniel, and A. L. Ulery. 2006. Vegetation and soil change following creosotebush (Larrea tridentata) control in the Chihuahuan desert. Journal of Arid Environments 64:152-173.

Peters, D. P. C. 2002. Recruitment potential of two perennial grasses with different growth forms at a semiarid-arid ecotone. American Journal of Botany 89:1616-1623.

Peters, D. P. C., B. T. Bestelmeyer, E. L. Fredrickson, J. E. Herrick, H. C. Monger, and K. M. Havstad. 2006. Disentangling complex landscapes: new insights to forecasting arid and semiarid system dynamics. BioScience 56:491-501.

Peterson, F. F. 1981. Landforms of the Basin and Range Province, defined for soil survey. Technical Bulletin 28, Reno, NV, USA: Agricultural Experiment Station, University of Nevada. $52 \mathrm{p}$.

Pringle, H. J. R., I. W. Watson, and K. L. Tinley. 2006. Landscape improvement, or ongoing degradation-reconciling apparent contradictions from the arid rangelands of Western Australia. Landscape Ecology 21:1267-1279.

Reynolds, J. F., P. R. Kemp, K. Ogle, and R. J. Fernandez. 2004. Modifying the "pulse-reserve" paradigm for deserts of North America: precipitation pulses, soil water, and plant responses. Oecologia 141:194-210.

Rietkerk, M., S. C. Dekker, P. C. de Ruiter, and J. van de Koppel. 2004. Self-organized patchiness and catastrophic shifts in ecosystems. Science 30:1926-1929.

Romme, W. H., C. D. Allen, J. D. Balley, W. L. Baker, B. T. Bestelmeyer, P. M. Brown, K. S. Elsenhart, L. Floyd-Hanna, D. W. Huffman, B. Jacobs, R. F. Miller, E. Muldavin, T. W. Swetnam, R. J. Tausch, and P. J. Weisberg. 2008. Historical and modern disturbance regimes, stand structures, and landscape dynamics in piñon-juniper vegetation of the western U.S. Fort Collins, CO, USA: Colorado Forest Restoration Institute. $35 \mathrm{p}$.

Sala, O. E., W. J. Parton, L. A. Joyce, and W. K. Lauenroth. 1988. Primary production of the central grassland region of the United States: spatial pattern and major controls. Ecology 69:40-45.
Scharf, F. S., F. Juanes, and M. Sutherland. 1998. Inferring ecological relationships from the edges of scatter diagrams: comparison of regression techniques. Ecology 79:448-460.

Scheffer, M., and S. R. Carpenter. 2003. Catastrophic regime shifts in ecosystems: linking theory to observation. Trends in Ecology and Evolution 18:648-656.

Schlesinger, W. H., J. F. Reynolds, G. L. Cunningham, L. F. Huenneke, W. M. Jarrell, R. A. VIRGINIA, AND W. G. Whitford. 1990. Biological feedbacks in global desertification. Science 247:1043-1048.

Schoeneberger, P. J., D. A. Wysocki, E. C. Benham, and W. D. Broderson [eds.]. 2002. Field book for describing and sampling soils. Version 2.0. Lincoln, NE, USA: Natural Resources Conservation Service, National Soil Survey Center.

Shiflet, T. N. 1973. Range sites and soils in the United States. In: D. N. Hyder [ed.]. Arid Shrublands: Proceedings of the Third Workshop of the U.S./Australia Rangeland Panel. Denver, C0, USA: Society for Range Management. p. 26-33.

Soll SuRveY Staff. 2006. Keys to soil taxonomy. 10th ed. Washington, DC, USA: US Department of Agriculture-Natural Resources Conservation Service. 332 p.

Stringham, T. K., W. C. Krueger, and P. L. Shaver. 2003. State and transition modeling: an ecological process approach. Journal of Range Management 56:106-113.

Swetnam, T. W., C. D. Allen, and J. L. Betancourt. 1999. Applied historical ecology: using the past to manage the future. Ecological Applications 9:1189-1206.

Tongway, D. J., AND N. L. HindLey. 2004. Landscape function analysis manual: procedures for monitoring and assessing landscapes with special reference to minesites and rangelands. Version 3.1. Canberra, Australia: CSIRO Sustainable Ecosystems. $80 \mathrm{p}$.

Tongway, D. J., C. Valentin, and J. Seghieri [eds.]. 2001. Banded vegetation patterning in arid and semiarid environments: ecological processes and consequences for management. Ecological Studies 149. New York, NY, USA: Springer-Verlag. $251 \mathrm{p}$.

Tugel, A. J., J. E. Herrick, J. R. Brown, M. J. Mausbach, W. Puckett, and K. Hipple. 2005. Soil change, soil survey, and natural resources decision making: a blueprint for action. Soil Science Society of America Journal 69:738-747.

Turner, R. M. 1990. Long-term vegetation change at a fully-protected Sonoran Desert site. Ecology 71:464-477.

[USDA-NRCS] US Department of Agriculture-Natural Resources Conservation Service. 2002. Gravelly ecological site description, SD-2. Available at: http:// www.nm.nrcs.usda.gov/technical/fotg/Section-2/esd/sd-2/R042XB010NM.pdf. Accessed 1 May 2007.

[USDA-NRCS] US Department of Agriculture-Natural Resources Conservation SERvice. 2003. National range and pasture handbook. Washington, DC, USA: US Department of Agriculture.

[USDA-NRCS] US Department of Agriculture-Natural Resources Conservation ServicE. 2007. National Soil Survey Handbook, title 430-VI. Available at: http://soils.usda.gov/technical/handbook/. Accessed 1 May 2007.

Wessels, K. J., S. D. Prince, and I. Reshef. 2008. Mapping land degradation by comparison of vegetation production to spatially derived estimates of potential production. Journal of Arid Environments 72:1940-1949.

West, N. L., F. L. Dougher, G. S. Manis, and R. D. Ramsey. 2005. A comprehensive ecological land classification for Utah's west desert. Western North American Naturalist 65:281-309.

Westoby, M., B. H. Walker, and I. Noy-MeiR. 1989. Opportunistic management for rangelands not at equilibrium. Journal of Range Management 42:266-274.

Winthers, E., D. Fallon, J. Haglund, T. Demeo, G. Nowacki, D. Tart, M. Ferwerda, G. Robertson, A. Gallegos, A. Rorick, D. T. Cleland, and W. Robbie. 2005. Terrestrial ecological unit inventory technical guide. Washington, DC, USA: US Department of Agriculture, Forest Service, Washington Office, Ecosystem Management Coordination Staff. $245 p$.

YAtes, C. J., AND R. J. HobBs. 1997. Woodland restoration in the Western Australian wheatbelt: conceptual framework using a state and transition model. Restoration Ecology 5:28-35.

ZonneveLd, I. S. 1989. The land unit-a fundamental unit in landscape ecology, and its applications. Landscape Ecology 3:67-86. 